\title{
Levels of Polyamines, Glutathione and Glutathione-Spermidine Conjugates during Growth of the Insect Trypanosomatid Crithidia fasciculata
}

\author{
By HELEN SHIM AND ALAN H. FAIRLAMB*† \\ Laboratory of Medical Biochemistry, The Rockefeller University, 1230 York Avenue, New York, \\ NY 10021, USA
}

(Received 13 July 1987; revised 12 October 1987)

\begin{abstract}
Levels of the polyamines spermidine and putrescine and the major intracellular thiols glutathione (GSH), glutathionylspermidine (GSH-SPD) and dihydrotrypanothione [bis(glutathionyl)spermidine); $\mathrm{T}[\mathrm{SH}]_{2}$ ] were measured by high performance liquid chromatography throughout the growth cycle of the insect trypanosomatid Crithidia fasciculata. The amount of total spermidine, putrescine and glutathione (free and conjugated to spermidine) was found to be elevated during growth. Of the total spermidine, 30 to $50 \%$ was found conjugated to glutathione during the exponential growth phase, increasing to 60 to $70 \%$ at stationary phase. $\mathrm{T}[\mathrm{SH}]_{2}$ was the principal intracellular thiol during exponential growth $\left(12.1\right.$ to $17.4 \mathrm{nmol}$ per $10^{8}$ cells), whereas GSH-SPD was the major thiol in stationary phase $\left(26.2 \mathrm{nmol}\right.$ per $10^{8}$ cells). GSH levels changed little during the growth cycle and represented a constant proportion (10 to $12 \%$ ) of the total intracellular glutathione. On dilution of stationary phase cells into fresh medium, a rapid decrease in GSH-SPD levels was observed to be associated with synthesis of T[SH $]_{2}$. This process reached $90 \%$ completion by $15 \mathrm{~min}$, with steady state achieved by $120 \mathrm{~min}$. As the total spermidine and glutathione pools did not increase during this interval, it could be calculated that this rapid redistribution of metabolites resulted in the release of $13 \mathrm{nmol}$ per $10^{8}$ cells unconjugated spermidine without de novo synthesis. This mechanism for rapidly elevating the intracellular concentration of free spermidine may be advantageous to this organism in rapidly adapting to favourable growth conditions.
\end{abstract}

\section{INTRODUCTION}

The polyamines putrescine, spermidine and spermine, and the tripeptide $\gamma$-glutamylcysteinylglycine (glutathione; GSH), are abundant components of most prokaryotic and eukaryotic cells (see reviews by Tabor \& Tabor, 1984; Pegg, 1986; Meister \& Anderson, 1983; Ziegler, 1985). These compounds are present intracellularly in millimolar concentrations and have been implicated in many important biological phenomena, including cell growth, cell differentiation and regulation of enzyme activity. However, despite a considerable amount of research into these areas, their precise roles in these regulatory functions remain obscure.

Trypanosomatids, including the parasites causing Leishmaniasis, Chagas' disease and African sleeping sickness, are unusual in that a considerable proportion of their intracellular spermidine and GSH are found as the conjugates $N^{1}$-mono-glutathionylspermidine (GSH-SPD) and as $N^{1}, N^{8}$-bis-(glutathionyl)spermidine ( $\mathrm{T}[\mathrm{SH}]_{2}$ ) (Fairlamb et al., 1986). The latter compound is thus far unique to the Trypanosomatidae and has been assigned the trivial name trypanothione (Fairlamb et al., 1985). These organisms contain neither glutathione reductase

† Present address: Department of Medical Protozoology, London School of Hygiene and Tropical Medicine, Keppel Street, London WC1E 7HT, UK.

Abbreviations: Trypanothione, $N^{1}, N^{8}$-bis-(glutathionyl)spermidine; $\mathrm{T}[\mathrm{SH}]_{2}$, dihydrotrypanothione; GSH, glutathione; GSH-SPD, glutathionylspermidine; ODC, ornithine decarboxylase. 
nor glutathione peroxidase (Fairlamb \& Cerami, 1985), but possess an analogous trypanothione reductase and trypanothione peroxidase system for the maintenance of intracellular thiols in the reduced state and for the removal of hydrogen peroxide (Henderson et al., 1987a; Fairlamb \& Henderson, 1987). Thus, trypanothione plays a central role in the cellular defence mechanisms of these organisms. The flavoprotein disulphide oxidoreductase (trypanothione reductase) has recently been purified and characterized from two species of trypanosomatid (Shames et al., 1986; Krauth-Siegel et al., 1987). Despite conservation of the catalytic site sequence of 14 amino acids identical to human glutathione reductase (Shames et al., 1986), trypanothione reductase will not use glutathione disulphide as a substrate. However, the enzyme is not completely specific in its requirement for trypanothione disulphide as a number of synthetic analogues will also serve as substrates, including glutathionylspermidine disulphide (Henderson et al., 1987b).

Previous studies of the biosynthetic pathway to $\mathrm{T}[\mathrm{SH}]_{2}$ in Crithidia fasciculata have shown that up to $50 \%$ of the intracellular spermidine is linked to peptide, the major component being $N^{1}$-glutathionylspermidine (Fairlamb et al., 1986). Glutathionylspermidine was originally identified in Escherichia coli under stationary phase and anaerobic conditions, where essentially all of the spermidine can be isolated as this derivative (Tabor \& Tabor, 1975). In contrast, little, if any glutathionylspermidine can be found in exponentially growing cells. Its function remains to be determined, but it has been suggested that spermidine or glutathione (or both) could be sequestered as glutathionylspermidine as a means of regulating cell division in E. coli (Tabor \& Tabor, 1970). In order to understand the function of this metabolite in trypanosomatids, we have examined the changes in concentrations of the polyamines putrescine and spermidine, and the principal intracellular thiols glutathione, glutathionylspermidine and trypanothione in $C$. fasciculata in various phases of growth.

\section{METHODS}

Organism and culture conditions. Crithidia fasciculata (wild-type) was routinely grown at $27^{\circ} \mathrm{C}$ in shaken culture (200 r.p.m.) in a series 25 incubator shaker (New Brunswick). The medium, containing yeast extract (Difco, $5 \mathrm{~g} \mathrm{l}^{-1}$ ), tryptone (Difco, $\left.4 \mathrm{~g} \mathrm{l}^{-1}\right)$, sucrose $\left(15 \mathrm{~g} \mathrm{l}^{-1}\right)$, Tween $80\left(5 \mathrm{~g} \mathrm{l}^{-1}\right)$, triethanolamine $\left(2.5 \mathrm{ml} \mathrm{l}^{-1}\right)$, pH adjusted to 8.0 with concentrated $\mathrm{HCl}$, was sterilized by autoclaving and supplemented with haemin (Gibco, $4 \mathrm{~g} \mathrm{l}^{-1}$ ) and streptomycin sulphate (Sigma, 0.2 $\mathrm{g} \mathrm{l}^{-1}$ ). Organisms were subcultured by dilution to $10^{6} \mathrm{cells}^{-1}$ with fresh medium every second day. The wild-type organism was cloned by plating appropriate dilutions on $1 \%(\mathrm{w} / \mathrm{v})$ agar prepared with the same medium. A single clone, designated WTC-HS6, was used in these studies.

Determination of thiols. Unless stated otherwise, cells were assayed without washing because this was found to affect the subsequent analyses (see Fig. 2). Routinely, $2 \times 10^{7}$ cells were pelleted in $1.5 \mathrm{ml}$ microcentrifuge tubes $(10000 \mathrm{~g}, 2 \mathrm{~min})$, the supernatant carefully aspirated and the cell pellet immediately resuspended with vigorous mixing in $0.05 \mathrm{ml} 40 \mathrm{~mm}-\mathrm{HEPPS} / \mathrm{NaOH}, 2 \mathrm{mM}-\mathrm{EDTA}, \mathrm{pH} 8.0$. Thiols were derivatized by the addition of $2 \mathrm{mM}$ monobromobimane in absolute ethanol $(0.05 \mathrm{ml})$ and heated at $70^{\circ} \mathrm{C}$ for $3 \mathrm{~min}$. After cooling, the samples were deproteinized with $4 \mathrm{M}$-methanesulphonic acid ( $\mathrm{pH} 1.5$ with solid $\mathrm{LiOH}$ ). After standing at $4{ }^{\circ} \mathrm{C}$ for $15 \mathrm{~min}$, denatured protein was removed by centrifugation (Eppendorf microcentrifuge; 10000 r.p.m., $2 \mathrm{~min}$ ), and the supernatant removed for analysis by high performance liquid chromatography (HPLC). Separation and analytical conditions were as described previously (Fairlamb et al., 1987). Thiol content is proportional to the number of cells extracted in the range $1 \times 10^{7}$ to $6 \times 10^{7}$. Larger quantities of cells can be derivatized by a proportional increase in reagents.

Determination of polyamines. Cells $\left(5 \times 10^{7}\right)$ were pelleted by centrifugation and extracted with $0.5 \mathrm{ml} 5 \%(\mathrm{w} / \mathrm{v})$ trichloroacetic acid $\left(4^{\circ} \mathrm{C}, 30 \mathrm{~min}\right)$. After centrifugation, the supernatant was extracted with ethyl acetate $(2 \mathrm{vols}, 5$ times), bubbled with nitrogen and taken to dryness under reduced pressure. Each sample was hydrolysed with $0.025 \mathrm{ml}$ propionic acid $/ \mathrm{HCl}$ at $160^{\circ} \mathrm{C}$ for $15 \mathrm{~min}$ (Westhall \& Hesser, 1974), dried under reduced pressure and resuspended in $0.2 \mathrm{ml} \mathrm{HPLC}$ solvent. After filtration samples and standards were analysed as previously described (Fairlamb et al., 1987).

Labelling studies and dilution experiments. Cells were cultured for $48 \mathrm{~h}$ in the presence of $1 \mu \mathrm{Ci}(37 \mathrm{kBq})$ $\left[{ }^{3} \mathrm{H}\right]$ spermidine $\mathrm{ml}^{-1}$ [22.5 $\mathrm{Ci} \mathrm{mmol}^{-1}(832.5 \mathrm{GBq})$; New England Nuclear]. Cell density was determined using a Neubauer haemocytometer at 48 and $52 \mathrm{~h}$ to establish that the organisms had reached stationary phase $(1.5$ to $1.9 \times 10^{8} \mathrm{ml}^{-1}$ ). Cells were then diluted to $2 \times 10^{7} \mathrm{ml}^{-1}$ with various media and incubated for up to $4 \mathrm{~h}$ at $27^{\circ} \mathrm{C}$ with shaking. All operations were done under sterile conditions. Samples were derivatized with monobromobimane before analysis. For ${ }^{3} \mathrm{H}$-labelling studies, the following HPLC gradient was used in order to increase resolution between spermidine and glutathionylspermidine: isocratic at $30 \%$ solvent $\mathrm{B}$ for $10 \mathrm{~min}$, followed by a linear gradient of 30 to $60 \%$ solvent B over $30 \mathrm{~min}$. The solvent composition and other analytical details were 
exactly as described by Fairlamb et al. (1987). Fractions $(1 \mathrm{ml})$ were collected and counted with $5 \mathrm{ml}$ Monofluor (National Diagnostics) for $10 \mathrm{~min}$ in a Beckman LS-7800 liquid scintillation counter.

Reagents. Chemically synthesized trypanothione and glutathionylspermidine were prepared as described previously (Henderson et al., 1986). Monobromobimane (Thiolyte reagent) and HEPPS (Ultrol brand) were purchased from Calbiochem; propan-1-ol (HPLC grade) was from Fluka; D-camphor sulphonate and methanesulphonic acid were from Aldrich. Other reagents were purchased from Fisher.

\section{RESULTS}

Initial experiments showed that $C$. fasciculata had a considerably higher thiol content than Trypanosoma brucei bloodstream or procyclic trypomastigote forms (Fairlamb et al., 1987; Bellofatto et al., 1987). At least a 4-fold excess of monobromobimane reagent was necessary for complete derivatization. Using the conditions described in Methods, thiol content was proportional to the number of cells derivatized in the range 1 to $6 \times 10^{7}$ organisms. Fig. 1 shows the results of a typical HPLC analysis. In stationary phase cells (normally between 1.5 and $1.9 \times 10^{8} \mathrm{ml}^{-1}$ ) the principal intracellular thiol was $N^{1}$-glutathionylspermidine (Fig. $1 b$ ), with GSH and $\mathrm{T}[\mathrm{SH}]_{2}$ accounting for 5 and $11 \%$, respectively, of the total intracellular glutathione.

(a)

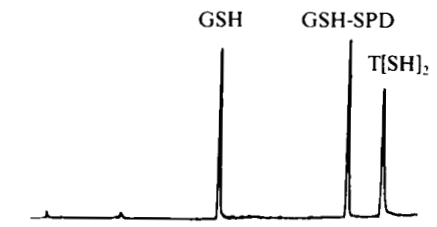

(b)

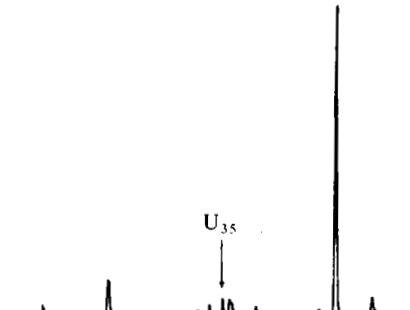

(c)

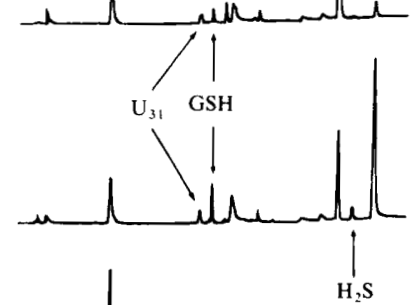

(d)

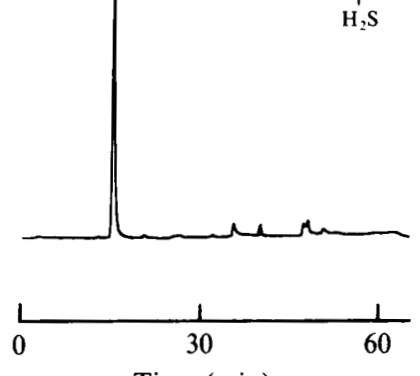

Time (min)

Fig. 1. Analysis of thiols in C. fasciculata by reversed phase HPLC. Compounds were detected by fluorescence of the monobromobimane derivatives prepared as described in Methods. Trace $(a)$, synthetic, purified standards $(80 \mathrm{pmol}$ of each); trace $(b)$, extract of stationary phase cells $(5 \mu \mathrm{l}$ from $2 \times 10^{7}$ cells); trace $(c)$, stationary phase cells $4 \mathrm{~h}$ after dilution into fresh medium $\left(5 \mu \mathrm{l}\right.$ from $2 \times 10^{7}$ cells); trace $(d)$, reagent blank $(5 \mu l)$. 


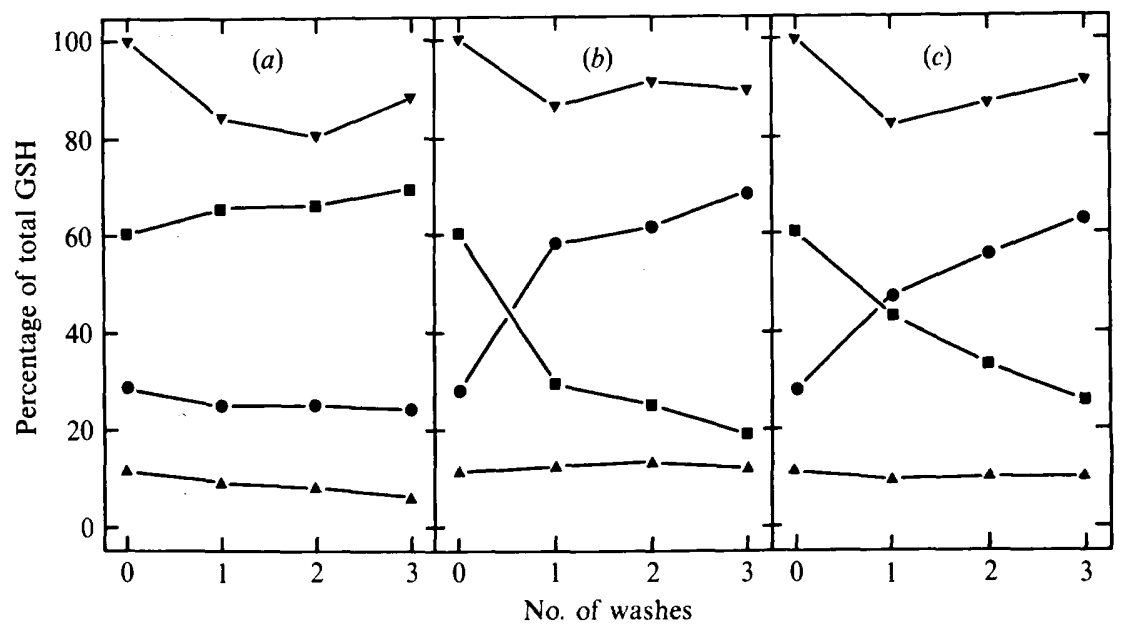

Fig. 2. Effect of washing cells on the percentage distribution of GSH in free GSH, GSH-SPD and $\mathrm{T}[\mathrm{SH}]_{2}$. Stationary phase cells $\left(2 \times 10^{7}\right)$ were sequentially washed by centrifugation $(10000$ r.p.m., $2 \mathrm{~min}$ ) and resuspending in $1.0 \mathrm{ml}$ of medium at $4{ }^{\circ} \mathrm{C}$. (a) Washed in spent medium, $\mathrm{pH} 4.9 ;(b)$ washed in PBS-glucose; $(c)$ as $(b)$ but omitting glucose. The percentage GSH was calculated as described in Table 1 (mean of duplicate analyses) for each sample. $\mathbf{A}$, Free GSH; , T[SH $]_{2} ; \boldsymbol{\square}, \mathrm{GSH}-\mathrm{SPD}$. The total GSH recovered $(\nabla)$ is expressed relative to the initial sample $\left(100 \%=34 \cdot 8 \mathrm{nmol}\right.$ per $10^{8}$ cells $)$.

Two additional minor fluorescent derivatives, eluting at approximately 31 and $35 \mathrm{~min}$, were found (Fig. $1 b$ ). Their structural identity remains to be determined. The other peaks are presumably hydrolysis products of the monobromobimane reagent since they were also present in the reagent blanks (Fig. 1d). A striking alteration in the levels of GSH-SPD and T[SH] occurred $4 \mathrm{~h}$ after dilution into fresh medium (Fig. $1 c$ ). The amount of GSH-SPD was reduced 3 to 4 -fold and $\mathrm{T}[\mathrm{SH}]_{2}$ increased about 10 -fold. In addition to the unknown compounds eluting at 31 and $35 \mathrm{~min}$, a small peak which co-eluted with $\mathrm{H}_{2} \mathrm{~S}$-bimane was observed. The amino acid cysteine eluted close to the large blank peak in Fig. $1(d)$ and could not be determined under these analytical conditions.

Our initial results with stationary phase cells were found to vary considerably from experiment to experiment, despite the fact that replicate assays yielded internally consistent results. The cause for this experimental variation was traced to two factors: the number of times the cells were washed and the pH of the washing medium (Fig. 2). If stationary phase cells were repeatedly pelleted by a brief centrifugation ( $2 \mathrm{~min}, 10000$ r.p.m.) and resuspended in supernatant medium obtained from stationary phase cultures ( $\mathrm{pH}$ in the range 4.5 to $5 \cdot 2$ ), GSHSPD was found as the principal form of the total intracellular GSH ( $>60 \%$ ) (Fig. $2 a$ ). In contrast, even after a single wash with cold PBS-glucose, the percentage of GSH found in GSHSPD and T[SH $]_{2}$ was reversed (Fig. $2 b$ ). This trend continued with subsequent washes. Washing with glucose-free PBS slowed this trend, but did not abolish it (Fig. 2c). Under all washing conditions, the total intracellular GSH decreased by 10 to $20 \%$. The reason for this was not investigated, but may be due to variable losses during centrifugation. This effect of $\mathrm{pH}$ did not appear to interfere with the derivatization reaction, because cells could be resuspended in HEPPS buffer, $\mathrm{pH} 8.0$, for up to $2 \mathrm{~min}$ before a significant change in thiol levels took place. Addition of the derivatization reagent was always completed 0.5 to $1 \mathrm{~min}$ after addition of HEPPS buffer.

The concentrations of polyamines and thiols in early exponential, late exponential and stationary phases of growth are summarized in Table 1. The levels of total spermidine and putrescine were decreased in non-dividing cells by 50 and $15 \%$, respectively, so that the ratio of putrescine to spermidine decreased from 1.30 to 0.72 between early exponential and stationary 
Table 1. Thiol and polyamine levels in C. fasciculata

\begin{abstract}
Mid-exponential-phase cells were diluted to $1 \times 10^{6} \mathrm{ml}^{-1}$ with fresh medium and samples removed after $3 \mathrm{~h}\left(1.7 \times 10^{6} \mathrm{ml}^{-1}\right), 24 \mathrm{~h}\left(4.0 \times 10^{7} \mathrm{ml}^{-1}\right)$ and $51 \mathrm{~h}\left(1.7 \times 10^{8} \mathrm{ml}^{-1}\right)$ for early exponential, late exponential and stationary phases of growth, respectively. Values are means ( \pm SEM where appropriate) for samples from six cultures from two experiments.
\end{abstract}

\begin{tabular}{|c|c|c|c|}
\hline \multirow[b]{2}{*}{ Metabolite } & \multicolumn{3}{|c|}{ Growth phase } \\
\hline & $\begin{array}{c}\text { Early } \\
\text { exponential }\end{array}$ & $\begin{array}{c}\text { Late } \\
\text { exponential }\end{array}$ & Stationary \\
\hline \multicolumn{4}{|l|}{ Content (nmol per $10^{8}$ cells) } \\
\hline $\begin{array}{l}\text { Total putrescine } \\
\text { Total spermidine } \\
\text { GSH } \\
\text { GSH-SPD } \\
\text { T[SH] } \\
\text { Total GSH* } \\
\text { Total spermidine peptide } \dagger\end{array}$ & $\begin{array}{r}74 \cdot 7 \pm 5 \cdot 0 \\
57 \cdot 4 \pm 5 \cdot 0 \\
5 \cdot 9 \pm 0 \cdot 9 \\
10 \cdot 4 \pm 1 \cdot 4 \\
17 \cdot 4 \pm 1 \cdot 9 \\
50 \cdot 9 \pm 6 \cdot 0 \\
27 \cdot 7 \pm 3 \cdot 3\end{array}$ & $\begin{array}{r}59 \cdot 9 \pm 4 \cdot 0 \\
70 \cdot 0 \pm 4 \cdot 5 \\
5 \cdot 1 \pm 0 \cdot 3 \\
11 \cdot 0 \pm 1 \cdot 2 \\
12 \cdot 1 \pm 0 \cdot 4 \\
40 \cdot 3 \pm 1 \cdot 2 \\
23 \cdot 1 \pm 1 \cdot 0\end{array}$ & $\begin{array}{r}35 \cdot 6 \pm 2 \cdot 7 \\
49 \cdot 0 \pm 2 \cdot 0 \\
3 \cdot 9 \pm 0 \cdot 7 \\
26 \cdot 2 \pm 0 \cdot 5 \\
4 \cdot 3 \pm 0 \cdot 5 \\
38 \cdot 7 \pm 1 \cdot 3 \\
30 \cdot 5 \pm 0 \cdot 4\end{array}$ \\
\hline \multicolumn{4}{|l|}{ Distribution $(\%)$} \\
\hline $\begin{array}{l}\text { Spermidine bound to GSH } \\
\text { GSH as free GSH } \\
\text { GSH as GSH-SPD } \\
\text { GSH as T[SH }]_{2}\end{array}$ & $\begin{array}{l}48 \cdot 3 \\
11 \cdot 5 \\
20 \cdot 4 \\
68 \cdot 1\end{array}$ & $\begin{array}{l}33 \cdot 0 \\
12 \cdot 6 \\
27 \cdot 3 \\
60 \cdot 1\end{array}$ & $\begin{array}{l}62 \cdot 2 \\
10 \cdot 0 \\
67 \cdot 6 \\
22 \cdot 4\end{array}$ \\
\hline \multicolumn{4}{|l|}{ Ratio } \\
\hline $\begin{array}{l}\text { Putrescine/spermidine } \\
\text { GSH-SPD/T[SH }]_{2}\end{array}$ & $\begin{array}{c}1.30 \pm 0.04 \\
0.60\end{array}$ & $\begin{array}{c}0.86 \pm 0.04 \\
0.91\end{array}$ & $0.72 \pm \underset{6.05}{0.03}$ \\
\hline
\end{tabular}

phase cells. A significant proportion of the intracellular spermidine was conjugated to glutathione throughout growth, reaching a maximum of $62 \%$ in stationary phase cells.

To confirm this finding and to examine whether significant quantities of spermidine were bound to oxidized glutathione or other metabolites, cells were grown to stationary phase in medium supplemented with $\left[{ }^{3} \mathrm{H}\right]$ spermidine. The cells which had incorporated approximately one-third of the label were then diluted with either fresh medium or spent medium and incubated at $27^{\circ} \mathrm{C}$ for a further $4 \mathrm{~h}$ before derivatization. Samples were then analysed for distribution of ${ }^{3} \mathrm{H}$-label into products (Table 2). As previously reported, no ${ }^{3} \mathrm{H}$-labelled spermine was found, indicating that these organisms are incapable of synthesizing this polyamine (Fairlamb et al., 1986). In addition, no ${ }^{3} \mathrm{H}$-label was detected where either trypanothione disulphide or glutathionylspermidine disulphide would have eluted, indicating that these oxidized components were not present in significant amounts in either stationary phase or lag phase cells. At $52 \mathrm{~h}, 57.9 \%$ of the ${ }^{3} \mathrm{H}$-label was found conjugated to GSH (Table 2), in good agreement with the value of $62.2 \%$ determined as the bimane derivative (Table 1). On further incubation in the same medium or after dilution with spent medium, the proportion of peptidebound spermidine increased to $71 \%$ of the total spermidine. In contrast, dilution into fresh medium resulted in a decrease in spermidine conjugates $(57.9 \%)$ and a redistribution of label into $\mathrm{T}[\mathrm{SH}]_{2}$ and free spermidine. De novo synthesis of unlabelled spermidine and subsequent incorporation into $\mathrm{T}[\mathrm{SH}]_{2}$ must have occurred during the $4 \mathrm{~h}$ incubation because the specific activity of $\mathrm{T}[\mathrm{SH}]_{2}$ was found to decrease by one-half compared to control cells at the beginning or end of the experiment or cells diluted in spent medium.

Table 1 also shows that the total amount of glutathione (free and conjugated) decreased between early exponential and stationary phase cells from 50.9 to $38.7 \mathrm{nmol}$ per $10^{8}$ cells, respectively. The reason for this decrease in total glutathione is not known, but may be due to cysteine starvation (see Table 4). Although the percentage of free GSH remained essentially unchanged, the relative distribution into $\mathrm{T}[\mathrm{SH}]_{2}$ and GSH-SPD underwent pronounced 


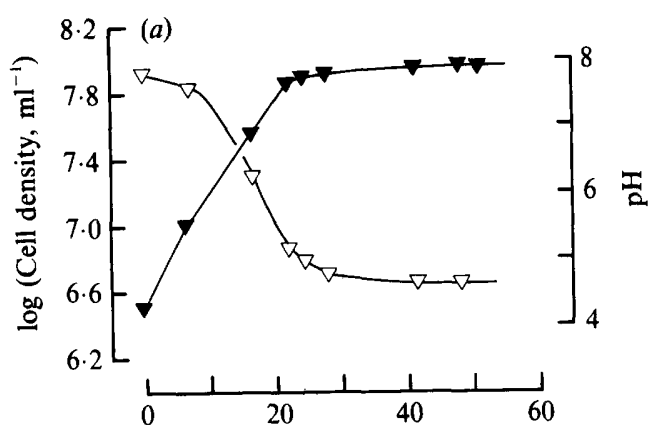

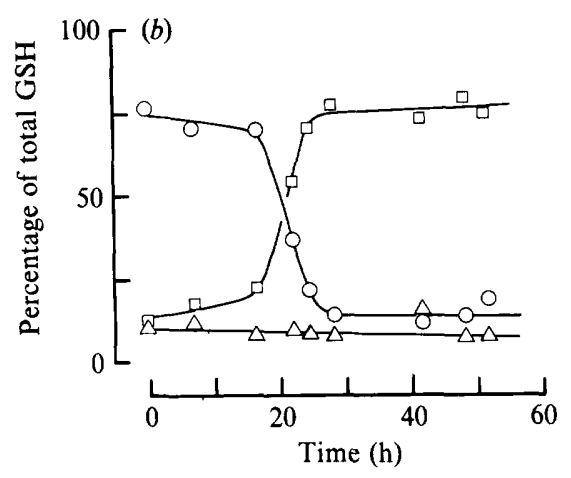

Fig. 3

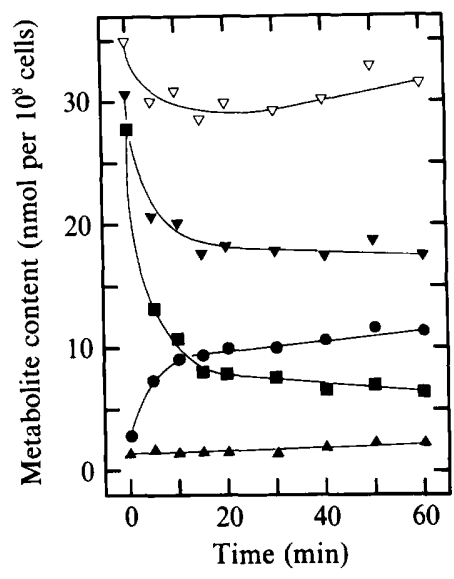

Fig. 4

Fig. 3. Distribution of glutathione and glutathionylspermidine conjugates during growth of $C$. fasciculata. (a) Cell density $(\nabla)$ and $\mathrm{pH}$ of the medium $(\nabla)$. (b) Percentage distribution as free GSH $(\triangle), \mathrm{T}[\mathrm{SH}]_{2}(\mathrm{O})$ and GSH-SPD $(\square)$. Each value is the mean of duplicate estimations.

Fig. 4. Effect of diluting stationary phase cells into fresh medium on absolute thiol content. Cells $\left(1.9 \times 10^{8} \mathrm{ml}^{-1}\right)$ were diluted to $2 \times 10^{7} \mathrm{ml}^{-1}$ with prewarmed $\left(27^{\circ} \mathrm{C}\right)$ medium and $1.0 \mathrm{ml}$ samples were withdrawn for analysis at intervals. $\nabla$, Total GSH;, , total GSH conjugated to spermidine; $\square$, GSH$\mathrm{SPD} ; \mathrm{O}, \mathrm{T}[\mathrm{SH}]_{2} ; \Delta$, free GSH.

\section{Table 2. Distribution of $\left[{ }^{3} \mathrm{H}\right]$ spermidine into conjugates in $\mathrm{C}$. fasciculata}

Before dilution the stationary phase culture $(52 \mathrm{~h})$ contained $1.5 \times 10^{8}$ cells $\mathrm{ml}^{-1}$. Each sample was analysed $4 \mathrm{~h}$ after dilution to $2 \times 10^{7}$ cells $\mathrm{ml}^{-1}$ with either spent medium, $\mathrm{pH} 5 \cdot 1$, or fresh medium, $\mathrm{pH} 8 \cdot \mathbf{0}$. Control cells were not diluted.

\begin{tabular}{|c|c|c|c|c|}
\hline & \multirow{2}{*}{$\begin{array}{l}\text { Before } \\
\text { dilution }\end{array}$} & \multicolumn{3}{|c|}{ After dilution } \\
\hline & & Control & Spent & Fresh \\
\hline Total GSH ${ }^{*}\left(\mathrm{nmol}\right.$ per $10^{8}$ cells $)$ & $33 \cdot 7$ & $32 \cdot 0$ & $34 \cdot 1$ & $49 \cdot 3$ \\
\hline \multicolumn{5}{|l|}{ Distribution of GSH (\%) } \\
\hline As free GSH & $4 \cdot 5$ & $4 \cdot 5$ & $4 \cdot 2$ & 6.5 \\
\hline As GSH-SPD & $84 \cdot 2$ & $85 \cdot 4$ & $84 \cdot 7$ & $18 \cdot 0$ \\
\hline As T[SH $]_{2}$ & $11 \cdot 3$ & $10 \cdot 2$ & $11 \cdot 1$ & $75 \cdot 6$ \\
\hline Total $\left[{ }^{3} \mathrm{H}\right]$ spermidine (c.p.m.) & 3090 & 2850 & 3180 & 2300 \\
\hline \multicolumn{5}{|l|}{ Distribution of spermidine (\%) } \\
\hline As free spermidine & $35 \cdot 1$ & 28.8 & $29 \cdot 4$ & $42 \cdot 1$ \\
\hline As GSH-SPD & $52 \cdot 3$ & $66 \cdot 3$ & $65 \cdot 6$ & $21 \cdot 1$ \\
\hline As $\mathrm{T}[\mathrm{SH}]_{2}$ & 5.6 & 4.9 & $5 \cdot 0$ & 36.8 \\
\hline \multicolumn{5}{|l|}{ Specific activity (c.p.m. nmol ${ }^{-1}$ ) } \\
\hline GSH-SPD & 2600 & 2800 & 2900 & 2200 \\
\hline $\mathrm{T}[\mathrm{SH}]_{2}$ & 3600 & 3400 & 3400 & 1800 \\
\hline
\end{tabular}

* Measured by HPLC after derivatization with monobromobimane. 


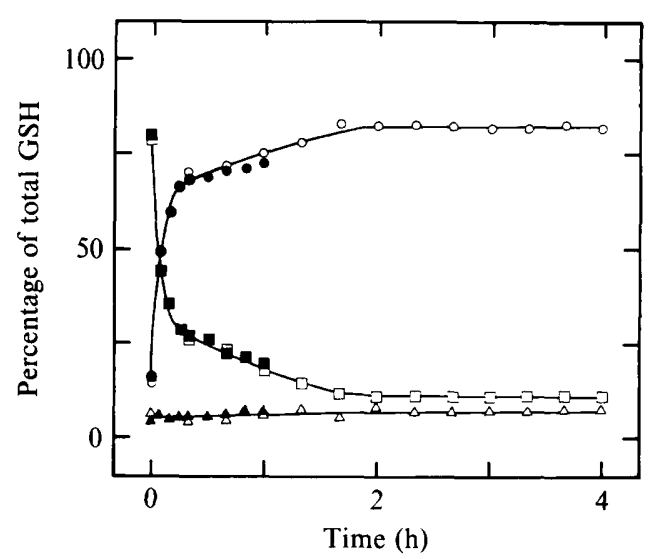

Fig. 5

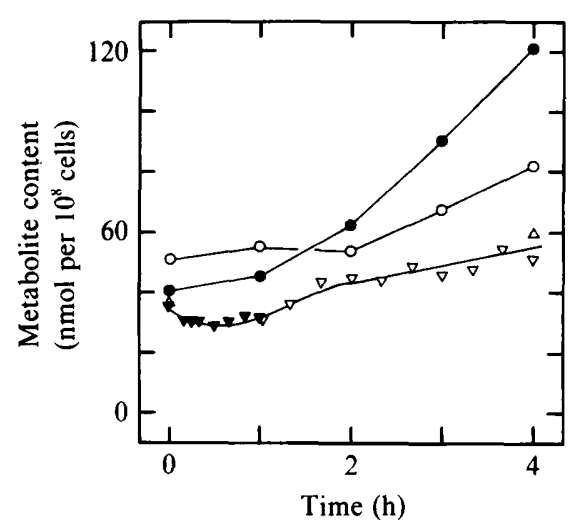

Fig. 6

Fig. 5. Effect of diluting stationary phase cells into fresh medium on the relative percentage distribution of GSH as free GSH $(\triangle, \Delta)$, as GSH-SPD $(\square, \square), T[S H]_{2}(O, O)$. Closed symbols, values calculated from the data given in Fig. 4; open symbols, values calculated from a separate experiment.

Fig. 6. Changes in total GSH, spermidine and putrescine on diluting stationary phase cells into fresh medium. Total GSH $(\nabla, \nabla)$, was calculated from the data shown in Figs 4 and 5 . Total spermidine $(O)$ and putrescine $(\odot)$ are from a separate experiment, in which total GSH $(\triangle)$ was determined for $0 \mathrm{~h}$ and $4 \mathrm{~h}$ time points only.

alteration during growth. In early and late exponential phases of growth, $\mathrm{T}[\mathrm{SH}]_{2}$ was the principal intracellular thiol ( $>60 \%$ of the total GSH), whereas GSH-SPD was the major thiol in stationary phase $(>60 \%)$.

In order to establish the point at which this transition from $\mathrm{T}[\mathrm{SH}]_{2}$ to GSH-SPD as principal thiol occurred, thiol levels were determined throughout the growth cycle (Fig. 3). During the exponential phase of growth the proportion of GSH found as T[SH $]_{2}$ and GSH-SPD changed little. However, at the transition from the exponential to the stationary phase of growth (20 to $24 \mathrm{~h}$ ), a rapid reciprocal change in the proportion of GSH bound to T[SH $]_{2}$ and GSH-SPD took place. This transition from $\mathrm{T}[\mathrm{SH}]_{2}$ to GSH-SPD as the principal form of GSH bound to spermidine also coincided with a fall in $\mathrm{pH}$ of the extracellular medium to below $\mathrm{pH} 5$. Comparable results were obtained in static cultures, even though stationary phase was reached at a lower cell density (not shown).

The kinetics of reversal of this effect were examined by diluting stationary phase cells into fresh medium. Fig. 4 shows the changes in concentration of GSH and GSH conjugates over the first $60 \mathrm{~min}$ following dilution. GSH-SPD decreased rapidly over the initial $15 \mathrm{~min}$, coincident with rapid net synthesis of $\mathrm{T}[\mathrm{SH}]_{2}$. Since free and total GSH levels remained essentially unchanged, and since no other metabolites of spermidine were found in the ${ }^{3} \mathrm{H}$-labelling experiment described in Table 2, the net result of this reshuffling of metabolites must have been the release of $12 \mathrm{nmol}$ unconjugated spermidine per $10^{8}$ cells. Fig. 5 shows that this process of redistribution of GSH into T[SH $]_{2}$ and GSH-SPD took place in two phases: a rapid initial phase that was completed within 15 to $20 \mathrm{~min}$, and a slower secondary phase that was completed after $2 \mathrm{~h}$. From 2 to $4 \mathrm{~h}$ the proportional distribution of GSH remained constant, despite the fact that the total GSH increased by $50 \%$ to $75 \%$ (Fig. 6). In this interval the cells were in the lag phase of growth since the absolute cell numbers were observed to increase by only $9 \%$. Fig. 6 also shows that no net synthesis of putrescine or spermidine occurred for 1 or $2 \mathrm{~h}$, respectively, indicating that the initial release of free spermidine (Fig. 4) preceded de novo spermidine synthesis. Since there was an increase in total spermidine by $4 \mathrm{~h}$ (Fig. 6) and a decrease in the specific activity of GSH-SPD and T[SH $]_{2}$ (Table 2), it can be inferred that the newly synthesized spermidine must also be incorporated into these peptides. 
Table 3. Effect of $p H$ of medium on thiol levels in C. fasciculata

Stationary phase cultures were diluted to $2 \times 10^{7}$ cells $\mathrm{ml}^{-1}$ and incubated at $28^{\circ} \mathrm{C}$ with shaking for $4 \mathrm{~h}$ before analysis. Values are means \pm SEM for duplicate samples from two or three experiments.

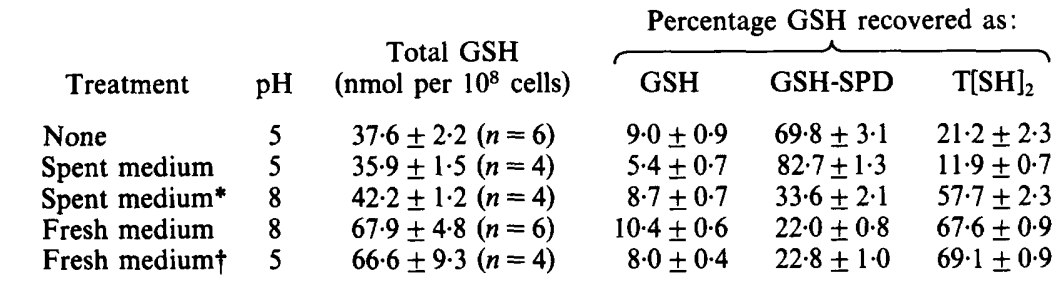

* Culture supernatant from stationary phase culture adjusted to $\mathrm{pH} 8$ with $5 \mathrm{M}-\mathrm{NaOH}$. $\uparrow$ Adjusted to $\mathrm{pH} 5$ with $5 \mathrm{M}-\mathrm{HCl}$

Table 4. Effect of amino acid precursors and glucose on thiol levels in C. fasciculata

Stationary phase cultures $\left(10 \mathrm{ml} ; 1.55 \times 10^{8}\right.$ cells ml-1) were supplemented with $100 \times$ stock solutions of the supplements indicated and incubated for $4 \mathrm{~h}$ before determination of thiol content. Final concentrations of supplements were $0.1 \mathrm{~mm}$ except for glucose which was present at $10 \mathrm{~mm}$.

\begin{tabular}{|c|c|c|c|c|c|}
\hline \multirow{2}{*}{$\begin{array}{c}\text { Time } \\
\text { (h) }\end{array}$} & \multirow[b]{2}{*}{ Supplement } & \multirow{2}{*}{$\begin{array}{l}\text { Total } \\
\text { GSH }\end{array}$} & \multicolumn{3}{|c|}{ Percentage GSH recovered as: } \\
\hline & & & GSH & GSH-SPD & $\mathrm{T}[\mathrm{SH}]_{2}$ \\
\hline 0 & None & $36 \cdot 1$ & $6 \cdot 5$ & $73 \cdot 2$ & $20 \cdot 4$ \\
\hline 4 & None & $40 \cdot 4$ & 6.5 & $72 \cdot 5$ & $21 \cdot 1$ \\
\hline 4 & Glucose & $37 \cdot 7$ & $7 \cdot 1$ & $74 \cdot 3$ & $18 \cdot 7$ \\
\hline 4 & Ornithine & $33 \cdot 1$ & 6.7 & $71 \cdot 3$ & $22 \cdot 0$ \\
\hline 4 & Glutamate & 41.9 & $6 \cdot 1$ & 72.5 & $21 \cdot 4$ \\
\hline 4 & Cysteine & $46 \cdot 4$ & 5.9 & 72.6 & 21.5 \\
\hline 4 & Methionine & $47 \cdot 4$ & 5.6 & 69.5 & 24.9 \\
\hline 4 & All of the above & $51 \cdot 4$ & 6.6 & $65 \cdot 3$ & $28 \cdot 1$ \\
\hline
\end{tabular}

The data presented so far suggest that limiting nutrients and the low $\mathrm{pH}$ of the medium may both have contributed to the changes in GSH-SPD and T[SH $]_{2}$ observed during growth. The role of $\mathrm{pH}$ in this phenomenon was examined by diluting cells into either fresh or spent medium that had been adjusted to either $\mathrm{pH} 5$ or $\mathrm{pH} 8$ (Table 3). Dilution with spent medium (pH 5) led to a further increase in GSH-SPD from 69.8 to $82.7 \%$ of the total GSH over $4 \mathrm{~h}$, at the expense of free GSH and T[SH $]_{2}$. Dilution in spent medium adjusted to $\mathrm{pH} 8$ led to a distribution of GSHSPD and $\mathrm{T}[\mathrm{SH}]_{2}$ that was intermediate between stationary phase and exponentially growing cells, associated with a small increase in the total pool size of GSH. However, $\mathrm{pH}$ per se was not the only factor involved in this process, because cells diluted into fresh medium at either $\mathrm{pH} 5$ or 8 showed identical patterns of GSH distribution.

The effect of supplementing stationary phase cultures with the precursor amino acids for biosynthesis of spermidine (ornithine and methionine) and glutathione (glutamate and cysteine) is shown in Table 4. Apart from a slight increase in total GSH in cultures supplemented with methionine or cysteine as sulphur source, none of the amino acids, alone or in combination, led to a reversal of the GSH-SPD:T[SH $]_{2}$ ratio. Thus, nutrient starvation did not appear to be responsible for the changes in thiols observed at stationary phase. Further support for this conclusion could be drawn from other experiments where cells were grown in the absence of haemin, an essential nutrient for these organisms (Kidder \& Dutta, 1958). Although stationary phase was reached at a 6-fold lower cell density than normal cultures, the percentage distribution of GSH was the same as controls (not shown). 
DISCUSSION

There has been considerable interest recently in the functions of polyamines and their relationship to chemotherapy in parasitic protozoa (see reviews by Bacchi, 1981; Bacchi \& McCann, 1987). Following the discovery of trypanothione a unique function for polyamines has been identified for the first time in uniflagellated protozoa (Fairlamb et al., 1985). Trypanothione is essential in these organisms for maintenance of intracellular thiol states and in defence against oxidative damage (see review by Fairlamb \& Henderson, 1987). Glutathionylspermidine has been identified also in $T$. brucei bloodstream (Fairlamb et al., 1987) and procyclic trypomastigotes (Bellofatto et al., 1987) and Leishmania (A. H. Fairlamb \& J. S. Keithly, unpublished) and is an intermediate in the biosynthetic pathway to $\mathrm{T}[\mathrm{SH}]_{2}$ (Fairlamb et al., 1986). Reduction of glutathionylspermidine disulphide does not necessarily require mediation by thiol-disulphide exchange with $\mathrm{T}[\mathrm{SH}]_{2}$, since this compound serves as an effective substrate for trypanothione reductase from either $C$. fasciculata (Henderson et al., 1987b) or Trypanosoma cruzi (Krauth-Siegel et al., 1987). Thus, the dramatic changes in levels of GSHSPD and $\mathrm{T}[\mathrm{SH}]_{2}$ during exponential and stationary phases would not be expected to seriously compromise the ability of the cell to regulate the intracellular thiol balance. The failure to detect glutathionylspermidine disulphide or trypanothione disulphide in $\left[{ }^{3} \mathrm{H}\right]$ spermidine labelled cells would tend to confirm this hypothesis.

Glutathionylspermidine was originally discovered in E. coli grown to stationary phase under acidic and anaerobic conditions (Tabor $\&$ Tabor, 1970, 1975). These authors suggested that sequestration of either spermidine or GSH (or both) may be a means of regulating levels of these important metabolites within the cell. The apparent absence of reports of GSH-SPD in other prokaryotes is puzzling. However, the presence of GSH-SPD in eukaryotic trypanosomatids suggests that the situation in E. coli can no longer be dismissed as a biochemical oddity of this bacterium and that it may be even more widespread than previously suspected.

The situation in $C$. fasciculata is a little more complex than in $E$. coli, in that $\mathrm{T}[\mathrm{SH}]_{2}$ is also present. E. coli does not contain this metabolite (Fairlamb \& Cerami, 1985; A. H. Fairlamb \& A. J. Tranguch, unpublished). Moreover, unlike $E$. coli, 30 to $50 \%$ of the intracellular spermidine is bound to GSH during exponential growth. However, it is important to note that the proportion of spermidine bound to GSH increases on transition from exponential to stationary phase such that it can be calculated that the amount of unconjugated spermidine decreases from $>30$ to $<20 \mathrm{nmol}$ per $10^{8}$ cells (Tables 1 and 2). Attempts to demonstrate complete conversion of $\left[{ }^{3} \mathrm{H}\right]$ spermidine to GSH-SPD as reported for $E$. coli (Tabor \& Tabor, $1970,1975$ ) have been unsuccessful (Table 2). This transition from T[SH $]_{2}$ to GSH-SPD as major thiol in C. fasciculata is associated with two events: cessation of growth and a decrease in $\mathrm{pH}$ of the medium (Fig. 3). The role of $\mathrm{pH}$ in this event is uncertain, but it is clearly not essential to the process since cells diluted in fresh medium at acid $\mathrm{pH}$ are able to reverse their GSHSPD : T[SH $]_{2}$ ratios (Table 3). On the other hand, partial reversal is observed when cells are washed in PBS or PBS-glucose (Fig. 2) or suspended in spent medium adjusted to pH 8 (Table 3). Possibly a change in extracellular $\mathrm{pH}$ leads to changes in intracellular $\mathrm{pH}$, thus affecting regulation of metabolic activity. Our previous studies on the biosynthesis of GSH-SPD and $\mathrm{T}[\mathrm{SH}]_{2}$ have demonstrated that these compounds are formed from GSH and spermidine by ATP-dependent enzyme catalysed reactions (Fairlamb et al., 1986). Whether the reverse process is also catalysed by the same enzymes or whether additional enzymes are involved is not clear at present. This can best be resolved by purification of the individual enzyme activities.

Our present experiments do not answer the question as to whether the change in GSH$\mathrm{SPD}: \mathrm{T}[\mathrm{SH}]_{2}$ ratio and the decrease in unconjugated spermidine actually cause cessation of cell growth or merely reflect it. A simple deficiency of the precursors can be excluded since supplementation with these compounds did not restore metabolite levels to those found in stationary or lag phase cells (Table 4).

In the case of restoration of cell growth, rapid metabolic reshuffling of GSH-SPD and T[SH $]_{2}$ was found to be $90 \%$ complete within 15 min with steady state reached by 120 min. Since total spermidine and GSH did not increase during this interval, it is clear that these effects preceded de novo spermidine or GSH biosynthesis (Fig. 6). These results are in agreement with those of 
Hannan et al. (1984), who found biphasic induction of the key regulatory enzyme ornithine decarboxylase (ODC) in a related trypanosomatid Leptomonas seymouri, with peaks at 2 and $8 \mathrm{~h}$ following dilution into fresh medium. Intriguingly, these authors noted that induction of ODC did not occur if cells were resuspended in either buffer alone or spent medium adjusted to $\mathrm{pH} 7 \cdot 2$. It would be of considerable interest to determine whether a similar pattern of induction of ODC also occurs in $C$, fasciculata.

The net result of this biochemical reshuffle of metabolites can be described by the following equation

\section{$2 \mathrm{GSH}-\mathrm{SPD} \rightleftharpoons \mathrm{T}[\mathrm{SH}]_{2}+$ spermidine}

which results in no net change in free GSH, but in the net release of $13 \mathrm{nmol}$ unconjugated spermidine per $10^{8}$ cells within 60 min (calculated from Fig. 4). As it can also be calculated that the difference in unconjugated spermidine in early exponential phase and stationary phase is $11.2 \mathrm{nmol}$ per $10^{8}$ cells (Table 1), these results strongly suggest that the function of the redistribution of GSH-SPD into T[SH $]_{2}$ may be to provide higher levels of spermidine necessary for growth. This may be advantageous to the organism in rapidly restoring macromolecular synthesis by minimizing the otherwise unavoidable delay of synthesizing polyamines de novo. Many of the parasitic trypanosomatids have complex digenetic life cycles involving an insect and mammalian host. If GSH-SPD:T[SH] $]_{2}$ levels are involved in regulation of cell differentiation, then interruption of their normal developmental cycle by chemotherapeutic means may form the basis for new treatments against these diseases.

This work was supported by grants from the National Institutes of Health (AI21429) and the UNDP/World Bank/WHO Special Programme for Research and Training in Tropical Diseases. The authors would like to thank Dr A. Cerami for his support and encouragement and Dr G. B. Henderson for supplying samples of trypanothione and glutathionylspermidine.

\section{REFERENCES}

BACCHI, C. J. (1981). Content, synthesis, and function of polyamines in Trypanosomatids: relationship to chemotherapy. Journal of Protozoology 28, 20-27.

BaCchi, C. J. \& McCanN, P. P. (1987). Parasitic protozoa and polyamines. In Inhibition of Polyamine Metabolism, pp. 317-344. Edited by P. P. McCann, A. E. Pegg \& A. Sjoerdsma. San Diego: Academic Press.

Bellofatto, V., Fairlamb, A. H., Henderson, G. B. \& Cross, G. A. M. (1987). Biochemical changes associated with $\alpha$-difluoromethylornithine uptake and resistance in Trypanosoma brucei. Molecular and Biochemical Parasitology 25, 227-238.

FaIRlamb, A. H. \& Cerami, A. (1985). Identification of a novel thiol-containing co-factor essential for glutathione reductase in trypanosomatids. Molecular and Biochemical Parasitology 14, 187-198.

Fairlamb, A. H. \& Henderson, G. B. (1987). Metabolism of trypanothione and glutathionylspermidine in trypanosomatids. In Host-Parasite Molecular Recognition and Interaction in Protozoal Infections, pp. 29-40. Edited by K.-P. Chang \& D. Snary. Heidelberg: NATO ASI Series.

Fairlamb, A. H., Blackburn, P., Ulrich, P., Chait, B. T. \& CERAMI, A. (1985). Trypanothione: a novel bis(glutathionyl)spermidine co-factor for glutathione reductase in trypanosomatids. Science 227, 1485-1487.

Fairlamb, A. H., Henderson, G. B. \& Cerami, A. (1986). The biosynthesis of trypanothione and $\mathrm{N}^{1}$ glutathionylspermidine in Crithidia fasciculata. Molecular and Biochemical Parasitology 21, 247-257.
Fairlamb, A. H., Henderson, G. B., Bacchi, C. J. \& Cerami, A. (1987). In vivo effects of difluoromethylornithine on trypanothione and polyamine levels in bloodstream forms of Trypanosoma brucei. Molecular and Biochemical Parasitology 24, 185-191.

Hannan, J. C., Bacchi, C. J. \& McCann, P. P. (1984). Induction of ornithine decarboxylase in Leptomonas seymouri. Molecular and Biochemical Parasitology 12, 117-124.

Henderson, G. B., Ulrich, P., Fairlamb, A. H. \& Cerami, A. (1986). Synthesis of the trypanosomatid metabolites trypanothione, and $\mathrm{N}^{1}$-mono- and $\mathrm{N}^{8}$ mono-glutathionylspermidine. Journal of the Chemical Society Chemical-Communications 593-594.

Henderson, G. B., Fairlamb, A. H. \& Cerami, A. (1987a). Trypanothione dependent peroxide metabolism in Crithidia fasciculata and Trypanosoma brucei. Molecular and Biochemical Parasitology 24, $39-45$.

Henderson, G. B., Fairlamb, A. H., Ulrich, P. \& Cerami, A. $(1987 b)$. Substrate specificity of the flavoprotein disulfide reductase from Crithidia fasciculata. Biochemistry 26, 3023-3027.

KIDDER, G. W. \& DUTTA, B. N. (1958). The growth and nutrition of Crithidia fasciculata. Journal of General Microbiology 18, 621-638.

KraUth-Siegel, R. L., Enders, B., Henderson, G. B., FAIRLAMB, A. H. \& SCHIRMER, R. H. (1987). Trypanothione reductase from Trypanosoma cruzi. Purification and characterization of the crystalline enzyme. European Journal of Biochemistry 164, 123128. 
Meister, A. \& ANderson, M. E. (1983). Glutathione. Annual Review of Biochemistry 52, 711-760.

PEgG, A. E. (1986). Recent advances in the biochemistry of polyamines in eukaryotes. Biochemical Journal 234, 249-262.

TABOR, C. E. \& TABOR, H. (1970). The complete conversion of spermidine to a peptide derivative in Escherichia coli. Biochemical and Biophysical Research Communications 41, 232-238.

TABOR, H. \& TABOR, C. E. (1975). Isolation, characterization, and turnover of glutathionylspermidine from Escherichia coli. Journal of Biological Chemistry 250, 2648-2654.

TABOR, C. E. \& TABor, H. (1984). Polyamines. Annual Review of Biochemistry 53, 749-790.
Shames, S. L., Fairlamb, A. H., Cerami, A. \& Walsh, C. T. (1986). Purification and characterization of trypanothione reductase from Crithidia fasciculata, a newly discovered member of the family of disulfidecontaining flavoprotein reductases. Biochemistry 25 , 3519-3526.

Westhall, F. \& Hesser, H. (1974). Fifteen-minute acid hydrolysis of peptides. Analytical Biochemistry 61, 610-613.

ZIEGLER, D. M. (1985). Role of reversible oxidationreduction of enzyme thiols-disulfides in metabolic regulation. Annual Review of Biochemistry 54, 305329. 